\title{
Prevention and management of sternal wound infections
}

\author{
Harold L. Lazar, MD, ${ }^{\mathrm{a}}$ Thomas Vander Salm, MD, ${ }^{\mathrm{b}}$ Richard Engelman, MD, ${ }^{\mathrm{c}}$ Dennis Orgill, $\mathrm{MD},{ }^{\mathrm{d}}$ and \\ Steven Gordon, $\mathrm{MD}^{\mathrm{e}}$
}

\footnotetext{
From the Divisions of ${ }^{\mathrm{a} C}$ Cardiac Surgery, Boston Medical Center; ${ }^{\mathrm{b}}$ Cardiac Surgery, Massachusetts General Hospital; 'Cardiac Surgery, Baystate Medical Center, Springfield; 'Plastic Surgery, Brigham and Women's Hospital, Boston, Mass; and ${ }^{\mathrm{e}}$ Infectious Diseases, The Cleveland Clinic, Cleveland, Ohio.

Disclosures: Authors have nothing to disclose with regard to commercial support.

Received for publication June 25, 2015; revisions received Dec 1, 2015; accepted for publication Jan 12, 2016; available ahead of print Aug 21, 2016.

Address for reprints: Harold L. Lazar, MD, Division of Cardiac Surgery, Boston Medical Center, 88 East Newton St, B402, Boston, MA 02118 (E-mail: harold.1.lazar@gmail.com).

J Thorac Cardiovasc Surg 2016;152:962-72

$0022-5223 / \$ 36.00$

Copyright (c) 2016 by The American Association for Thoracic Surgery

http://dx.doi.org/10.1016/j.jtcvs.2016.01.060
}

Although the incidence of sternal wound infections has decreased to $1 \%$ to $4 \%$ of all cardiac surgery procedures, they continue to be associated with increased morbidity and mortality, and decreased long-term life expectancy. ${ }^{1-3}$ They prolong hospital length of stay and can raise hospital costs by as much as US\$62,000. ${ }^{4}$ Sternal wound infections are now publicly reported, and the US Center for Medicare and Medicaid services will no longer reimburse hospital costs incurred in the treatment of deep sternal wound infections (DSWI) following coronary artery bypass graft (CABG) surgery. ${ }^{5}$

Despite the significant clinical and economic consequences of sternal wound infections, there are currently no specific guidelines in cardiac surgery for the prevention and treatment of sternal wound infections. What follows are recommendations for the prevention of wound infections during the preoperative, intraoperative, and postoperative periods, as well as principles for the most effective methods and techniques to treat sternal wound infections to achieve the lowest morbidity and mortality as derived from evidence-based recommendations (Tables 1 and 2).

\section{METHODS}

A literature search was performed using PubMed and Google Scholar up to March 2015 using the MeSH headings "Sternal Wound Infections Prevention and Treatment," "Treatment of Mediastinitis," "Topical Antibiotics in Cardiac Surgery," "Wound VAC Therapy for Sternal Wound Infections," and "Prevention and Treatment of Sternal Instability." Editorials and articles involving prevention and therapy for wound infections in noncardiac, nonsternotomy patients were excluded.

The systemic review was reported according to the Preferred Reporting Items for Systemic Reviews and Meta-Analyses (PRISMA) guidelines ${ }^{6}$ (Figure 1).

\section{DEFINITIONS}

In defining sternal wound infections it is important to distinguish between DSWI and superficial sternal wound infections (SSWI). ${ }^{7,8}$

A SSWI involves only the skin, subcutaneous tissue, and/or pectoralis fascia. There is no bony involvement. The incidence of SSWI ranges from $0.5 \%$ to $8 \%$ with a combined morbidity and mortality of $0.5 \%$ to $9 \%{ }^{7}$

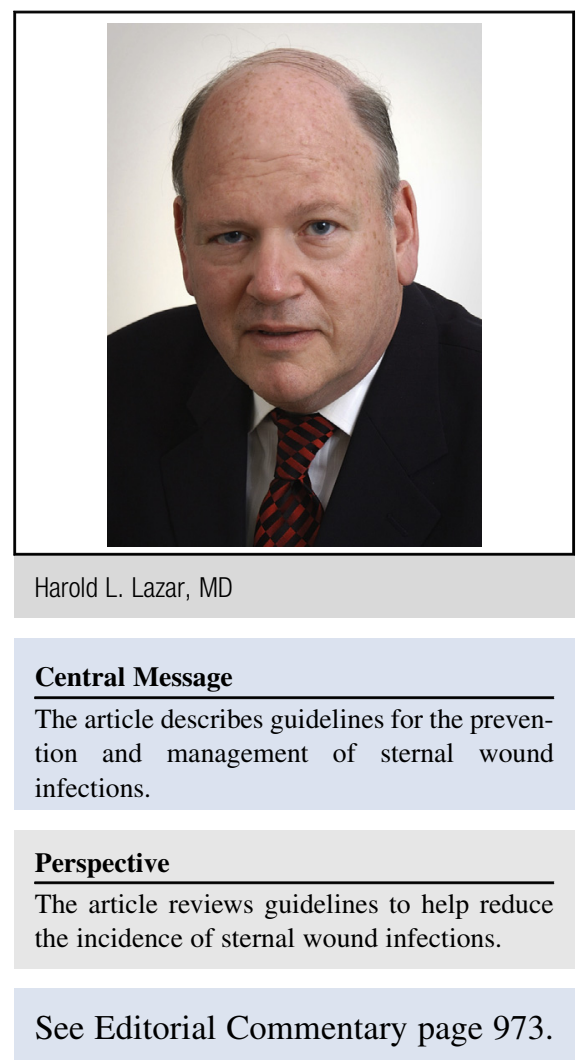

As defined by the Centers for Disease Control and Prevention, DSWI require the presence of one of the following criteria: (1) an organism isolated from culture of mediastinal tissue or fluid; (2) evidence of mediastinitis seen during operation; or (3) presence of either chest pain, sternal instability, or fever $\left(>38^{\circ} \mathrm{C}\right)$, and purulent drainage from the mediastinum, or isolation of an organism present in a blood culture or a culture of the mediastinal area. ${ }^{8}$ Although the incidence of DSWI reported from 217,829 cardiac surgery procedures for 2013 in the Society of Thoracic Surgeons Adult Cardiac Surgery Database was less than $1 \%$, the morbidity can be as high as $40 \%$ in some series.

Scanning this QR code will take you to the article title page. 


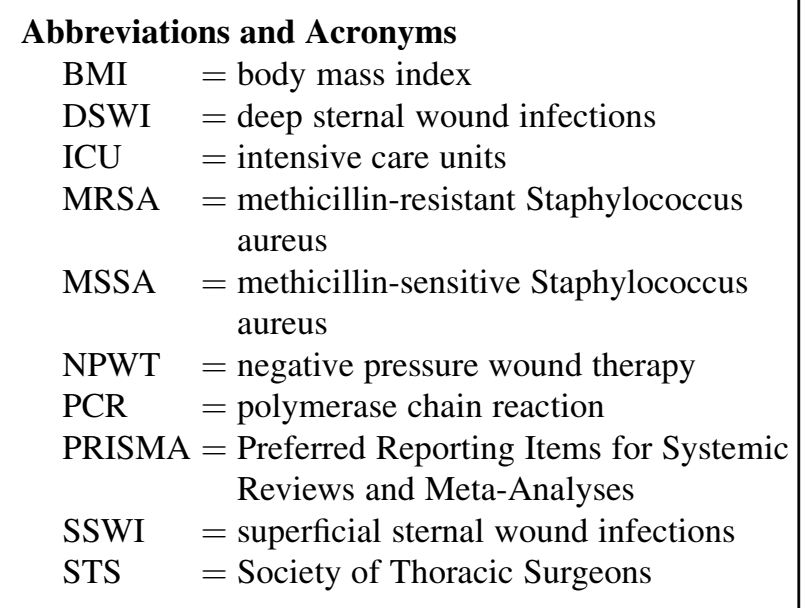

\section{PREOPERATIVE PREVENTION}

\section{Screening for Nasal Carriers of Staphylococcus}

- All cardiac surgery patients should have nasal swabs or polymerase chain reaction (PCR) testing, if available, before surgery.

\section{Class I Recommendation; Level of Evidence $=$ A.}

Most cardiac surgical wound infections are caused by Staphylococcus species. Most of these infections arise from the patient's own nasal flora. Twenty to thirty percent of the general population are carriers of Staphylococcus aureus. ${ }^{9}$ The risk of a $S$ aureus infection is increased 3-fold in patients who are carriers of $S$ aureus. ${ }^{10}$ Although $5 \%$ to $15 \%$ of patients admitted to intensive care units (ICUs) are methicillin-resistant $S$ aureus (MRSA) carriers, the risk of MRSA bacteremia postoperatively is significantly higher in these patients than the risk of a methicillin-sensitive $S$ aureus (MSSA) bacteremia in MSSA carriers. ${ }^{11}$ PCR assays provide rapid screening ( $<12$ hours) for carriers of Staphylococcus. However, the assay adds to the cost of screening and is not available in all hospitals. Intranasal mupirocin results in immediate decolonization of MSSA in $>90 \%$ of cases. ${ }^{12}$ However, it results in decolonization of only $45 \%$ to $50 \%$ of patients with MRSA. ${ }^{13,14}$

\section{Nasal Disinfectants}

- Routine mupirocin administration is recommended for all cardiac surgery procedures in the absence of PCR testing or nasal cultures positive for staphylococcal colonization.

Class I Recommendation; Level of Evidence $=A$.

DNA fingerprint analyses have demonstrated that the genotype of $S$ aureus isolates recovered from the sternum of patients with mediastinal wound infections and the nares are identical. ${ }^{15}$
TABLE 1. Classification of recommendation and level of evidence

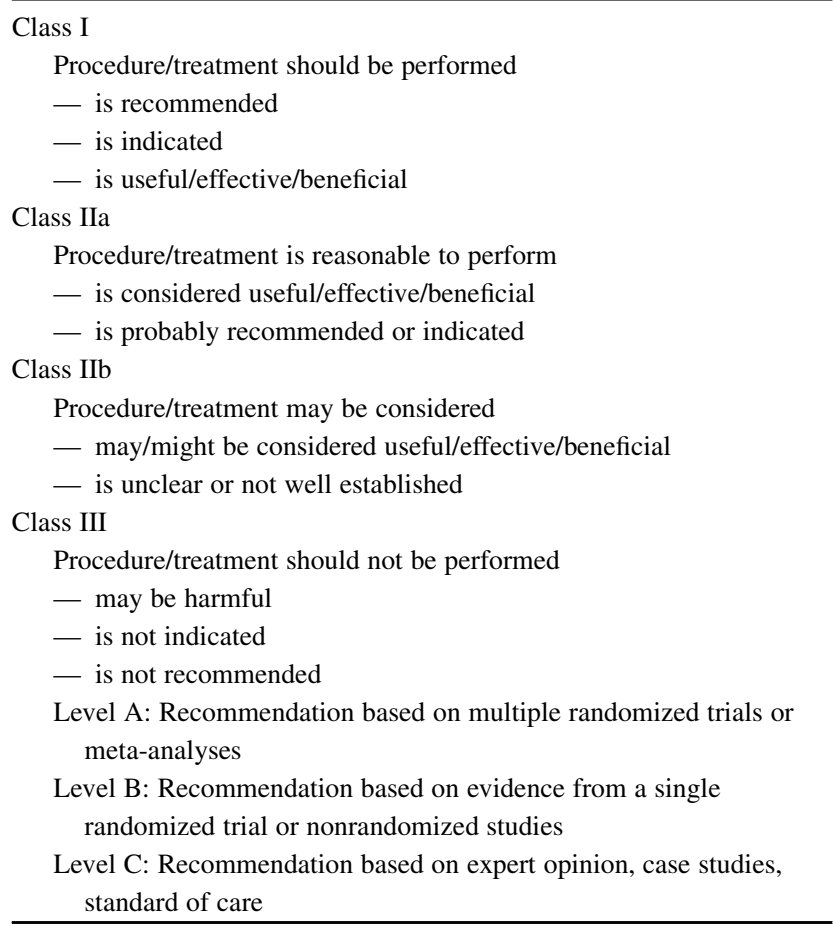

Cimochowski and colleagues ${ }^{16}$ found that mupirocin significantly decreased the incidence of sternal wound infections in a single-center, retrospective study involving a cohort of patients who underwent cardiac surgery. Topical intranasal therapies have emerged as the preferred method to eradicate staphylococcal colonization, and mupirocin has emerged as the topical antibiotic agent of choice for elimination of $S$ aureus in nasal carriers. In a randomized, double-blind, placebo-controlled, multicenter trial involving both cardiac and noncardiac surgical patients, 2\% mupirocin ointment (Bactroban; GlaxoSmithKline, Research Triangle Park, NC) in combination with chlorhexidine gluconate soap significantly decreased the incidence of DSWI and hospital length of stay. ${ }^{17} \mathrm{Car}-$ riers of Staphylococcus were rapidly detected by PCR testing, and mupirocin was initiated within 24 hours of surgery and continued for 5 days. Other studies have found no effect of mupirocin treatment in the incidence of wound infections. ${ }^{18-22}$ However, subgroup analyses of these studies showed that there was a significant decrease in wound infections in patients who had positive nasal cultures for Staphylococcus organisms who were treated with mupirocin. There are several reasons for the lack of the therapeutic effect of mupirocin in these studies. Many were performed in patients with a low risk for infection. The incidence of wound infection was small, and the studies were underpowered to detect differences in therapeutic interventions. Because mupirocin has minimal 
Records identified through database screening

$\mathrm{n}=174$

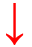

$\downarrow$

Records after duplicates removed

$\mathrm{n}=174$

Records screened

$\mathrm{n}=174$<smiles>[AlH]</smiles>

Full text articles

assessed for eligibility

$\mathrm{n}=150$<smiles>C1CCC1</smiles>

Studies included for

qualitative synthesis

$\mathrm{n}=150$

Studies included in

quantitative synthesis

(meta-analysis)

$\mathrm{n}=150$
Additional records identified through other sources

$\mathrm{n}=0$

Records excluded

$\mathrm{n}=24$

Records excluded

$\mathrm{n}=24$

Full text excluded

with reasons

$\mathrm{n}=24$

17 articles had only a minority of cardiac surgery patients

$\downarrow$

7 articles were review articles

FIGURE 1. PRISMA flow diagram.

effects in reducing infection in noncolonized patients, this dilutes the power of these studies.

Nasal mupirocin has no effect in patients who are not nasal carriers of Staphylococcus or in patients with a negative PCR assay. Hence, mupirocin nasal therapy should only be used in those patients who have either a positive result on nasal culture or PCR assay and in those patients whose culture results are not available or not obtained at the time of surgery. 


\section{Preoperative Bathing}

- Presurgical bathing with chlorhexidine may be helpful in reducing skin bacterial counts.

Class IIb Recommendation; Level of Evidence $=B$.

Although chlorhexidine reduced skin bacterial counts to a greater extent than other agents, in 3 randomized, controlled trials, there was no difference in the postoperative infection rates between patients who showered with chlorhexidine, povidone-iodine, soap and water, or placebo. ${ }^{23}$ Kuhme and colleagues ${ }^{24}$ isolated coagulase-negative staphylococci and Propionibacterium acnes from the subcutaneous tissue in $89 \%$ of patients undergoing cardiac surgery and from the skin surrounding the wound in $98 \%$ of those patients who washed with a preoperative chlorhexidine scrub. The authors concluded that skin preparation with chlorhexidine alone cannot prevent skin flora organisms from contaminating the wound and surrounding tissue during cardiac surgical procedures, but will reduce bacterial counts.

\section{Hypoalbuminemia and Poor Nutritional Status}

- Preoperative hypoalbuminemia is associated with an increased risk for sternal wound infections and should be corrected before surgery if possible.

\section{Class I Recommendation; Level of Evidence $=B$.}

Patients with preoperative hypoalbuminemia $(<3.0 \mathrm{~g} / \mathrm{mL})$ are more likely to develop DSWI following cardiac surgery. ${ }^{25}$ In 5168 patients undergoing cardiac surgical procedures requiring a median sternotomy, Engelman and colleagues ${ }^{26}$ showed that a preoperative serum albumin level $<2.5 \mathrm{~g} / \mathrm{mL}$ was independently associated with both increased mortality and an increased incidence of sternal wound infections. Similar findings were reported by Ulicny and Hiratzka $^{27}$ in a review of patients with preoperative malnutrition undergoing cardiac surgery procedures. Although there are now many biomarkers of poor preoperative nutritional status, in most large multicenter trials, a low serum albumin level continues to be one of the strongest predictors of postoperative morbidity and mortality. ${ }^{28}$ This is especially true for elderly patients undergoing cardiac surgery. ${ }^{29}$ Patients with a serum albumin level $<2.5 \mathrm{mg} / \mathrm{dL}$, significant weight loss $(>10 \%$ of body weight within 6 months), and muscle wasting are those who would benefit most from preoperative nutritional support. ${ }^{30,31}$ Patients who are candidates for preoperative nutritional support should be those in whom surgery can be safely delayed for 7 to 10 days, the length of time that preoperative nutritional support is recommended..$^{32}$ It should be given through the enteral route, which avoids infections and metabolic complications and is safer and more cost effective. $^{32}$

Most trials evaluating the potential benefits of preoperative nutritional support are small, and most of the patients have undergone abdominal surgical procedures. Nevertheless, the evidence appears to justify preoperative nutritional support when surgery can be safely delayed. In a multicenter trial involving patients undergoing mostly abdominal procedures with severe preoperative malnourishment, preoperative nutritional support resulted in a significant decrease in all major complications including wound infections $(25.6 \%$ vs $50.6 \%){ }^{33}$

\section{Remote Infections}

- All distant, extrathoracic infections should be treated before cardiac surgical procedures.

Class I Recommendation; Level of the Evidence $=C$.

Infections at a site remote from the surgical wound have been linked to a 3 - to 5 -fold increase in wound infections. ${ }^{34}$ Whenever possible, in nonemergent cases, it is advisable to identify and treat all infections remote from the surgical site before surgery and postpone surgery in patients who are clinically stable until the infection has resolved. ${ }^{35,36}$

\section{Preoperative Glycemic Control}

- Optimizing glycemic control is recommended in patients with increased HbA1c levels (>7.5) and serum glucose levels $>200 \mathrm{mg} / \mathrm{dL}$ before any cardiac surgery procedure.

Class I Recommendation; Level of the Evidence $=B$.

Efforts should be made to optimize glucose control before surgery because this has been associated with an increased incidence of DSWI. ${ }^{37}$ In those patients who require urgent or emergent surgery in whom serum glucose levels are persistently $>180 \mathrm{mg} / \mathrm{dL}$, intravenous insulin infusions are the most effective method to rapidly achieve glycemic control. These infusions should be continued in the intra- and postoperative periods if necessary to maintain serum glucose levels $<180 \mathrm{mg} / \mathrm{dL} .{ }^{38}$

\section{Smoking Cessation}

- Smoking cessation and aggressive pulmonary toilet should be performed in patients who are active smokers and those with chronic obstructive pulmonary disease.

\section{Class I Recommendation; Level of Evidence $=B$.}

There is convincing evidence that patients who are active smokers at the time of cardiac surgery have a higher incidence of infectious complications and increased mortality. ${ }^{39,40}$ In a large prospective study, Nagachinta 
and colleagues ${ }^{41}$ found that smoking was an independent risk factor for sternal and mediastinal infections following cardiac surgery. It is recommended that, whenever possible, smoking cessation be initiated for at least 30 days before surgery. ${ }^{35,36}$

\section{Preoperative Antibiotics}

In 2006-2007, the Society of Thoracic Surgeons Workforce on Evidence-Based Medicine published guidelines for the duration and choice of antibiotics in cardiac surgery. ${ }^{42,43}$ What follows is a summary of their recommendations for the use of preoperative antibiotics to prevent sternal wound infections.

- A cephalosporin, either cefazolin or cefuroxime, should be given intravenously within 60 minutes before the skin incision and be continued for no longer than 48 hours.

Class I Recommendation; Level of Evidence $=A$.

Weight-based dosing is recommended and redosing is indicated for procedures $>4$ hours.

- Vancomycin is reserved for patients with a history of type 1 allergic reactions to $\beta$-lactam agents or in cases where MRSA is a special concern.

\section{Class IIa Recommendation; Level of Evidence $=B$.}

MRSA should be a special concern in patients hospitalized for $>3$ days, patients transferred from another inpatient facility, procedures involving an intracardiac implant or a vascular graft, and institutions with a high prevalence of MRSA.

- Vancomycin is not recommended as the sole prophylactic antibiotic for cardiac surgery procedures.

\section{Class III Recommendation; Level of Evidence $=B$.}

Unlike $\beta$-lactam antibiotics, vancomycin has a narrower antimicrobial spectrum, inferior tissue and bone penetration, less desirable pharmacokinetics, and slower bactericidal effects compared with cephalosporins. ${ }^{42,43}$ Its activity is essentially limited to gram-positive bacteria, especially MRSA and methicillin-resistant Staphylococcus epidermidis. It is considerably less active than either nafcillin or oxacillin against $S$ aureus species, which are the most common organisms found in DSWI.

- An antimicrobial with gram-negative coverage should be added when vancomycin is the primary prophylactic antibiotic.

Class IIb Recommendation; Level of the Evidence $=C$.

In patients with a $\beta$-lactum or penicillin allergy, vancomycin is considered to be the best prophylactic antibiotic because of its coverage of MRSA, but there are concerns about the absence of gram-negative coverage. Therefore, the addition of an aminoglycoside, usually gentamycin or other suitable antimicrobials, is recommended. It is recognized that vancomycin combined with an aminoglycoside is associated with both nephrotoxicity and ototoxicity, with delayed excretion after cardiopulmonary bypass. Therefore, a single preoperative dose or, at most, a second postoperative dose of no more than $4 \mathrm{mg} / \mathrm{kg}$ is recommended. ${ }^{44}$ It is reasonable, however, to use vancomycin in conjunction with a non-nephrotoxic antimicrobial up to 48 hours postoperatively.

\section{INTRAOPERATIVE PREVENTION}

Vancomycin intravenously combined with vancomycin with sternal paste should be used with caution, and monitoring of serum level vancomycin is recommended.

\section{Antibiotics}

- A cephalosporin should be administered within 60 minutes of a cardiac surgical procedure and redosed for procedures lasting $>4$ hours.

\section{Class I Recommendation; Level of Evidence $=A$.}

Studies have shown that intraoperative redosing of cefazolin reduced infections by $16 \%$ in procedures lasting more than 4 hours, ${ }^{45}$ and after 120 minutes of cardiopulmonary bypass. ${ }^{46}$ Some institutions routinely administer cefazolin for 48 hours.

\section{Glycemic Control}

- Continuous insulin infusion should be initiated to maintain serum glucose level $<180 \mathrm{mg} / \mathrm{dL}$.

Class I Recommendation; Level of the Evidence $=A$.

Studies have shown that increased glucose levels $(>200 \mathrm{mg} / \mathrm{dL}$ ) in the intraoperative period is an independent risk factor for postoperative sternal wound infections. ${ }^{47-49}$ Multiple studies have shown that maintaining serum glucose level $<180 \mathrm{mg} / \mathrm{dL}$ during surgery significantly decreases the incidence of sternal wound infections. ${ }^{37,38,50}$ This is best done with a continuous insulin infusion.

\section{Topical Antibiotics}

- Topical antibiotics should be applied to the cut edges of the sternum on opening and before closing all cardiac surgical procedures involving a sternotomy.

Class I Recommendation; Level of Evidence $=B$. 
Topical antibiotics applied to the cut edges of the sternum have been found to significantly reduce the incidence of sternal wound infections.

In a blinded, prospective, randomized trial involving 416 patients undergoing a median sternotomy, Vander Salm and colleagues $^{51}$ found that topical vancomycin, in conjunction with preoperative antibiotics, significantly reduced the incidence of sternal wound infections from $3.6 \%$ to $0.5 \% ; P=.02$. Lazar and colleagues ${ }^{52}$ in a retrospective, nonrandomized, single-center study involving over 3000 patients who underwent cardiac surgery found that topical vancomycin ( $2.5 \mathrm{~g}$ in $2 \mathrm{~mL}$ of normal saline) applied as a slurry to both edges of the sternum along with perioperative antibiotics and tight glycemic control $(<180 \mathrm{mg} / \mathrm{dL})$ resulted in the total elimination of superficial $(0 \%$ vs $1.6 \% ; P<.001)$, deep $(0 \%$ vs $0.7 \% ; P=.005)$, or any type of wound infection in both nondiabetic $(0 \%$ vs $2.2 \% ; P<.0001)$ and diabetic patients $(0 \%$ vs $3.3 \%$; $P=.0004)$. In a retrospective study involving over 1000 patients, Arruda and colleagues ${ }^{53}$ reduced the incidence of sternal wound infections to $0.5 \%$ using vancomycin paste. In a subanalysis, Lazar and colleagues ${ }^{54}$ found that serum vancomycin levels returned to baseline on the sixth postoperative day. Vancomycin paste was not associated with an increased incidence of any drug-resistant infections or contribute to postoperative renal toxicity.

Gentamicin-collagen sponges have also been shown to significantly decrease the incidence of sternal wound infections. ${ }^{55-58}$ However, a large multicenter trial failed to show any benefits with these sponges. ${ }^{59}$ Recently, Kowalewski and colleagues ${ }^{60}$ showed, in a meta-analysis, that gentamicin sponges significantly reduced the incidence of both superficial and deep wound infections by $40 \%$. Furthermore, they noted that failure to follow the manufacturer's instructions to limit the exposure of the gentamicin sponges in saline before implantation resulted in a lower concentration of gentamicin and that this was responsible for the negative results in the earlier study by Bennett-Guerrero and colleagues. ${ }^{59}$

\section{Bone Wax}

- Bone wax is not recommended for application to the cut edges of the sternum.

\section{Class III Recommendation; Level of Evidence $=B$.}

Bone wax acts as a foreign body and has been shown to prevent bone union. ${ }^{61-63}$ It impairs the ability of bone to clear bacteria and has been found to be an independent risk factor for sternal dehiscence and wound infections. ${ }^{64}$ It has not been associated with a decreased risk of blood loss or blood product use. ${ }^{64}$ Although some studies have failed to show an increase in wound infections in patients with bone wax, it has not decreased the incidence of infections or resulted in decreased blood loss. ${ }^{65-67}$ Because it may increase the risk of infection and there are other substances such as vancomycin paste that are both hemostatic and have been shown to significantly decrease wound infections, bone wax should not be used in patients undergoing a median sternotomy.

\section{Intraoperative Surgical Techniques}

Properly opening and closing the sternum will decrease the incidence of sternal dehiscence and subsequent sternal infections. An inadvertent paramedian sternotomy makes it difficult to properly realign the sternum and leads to instability, dehiscence, and ultimately infection. ${ }^{68}$

- Closing the sternum with a figure-of-eight technique may be preferable to prevent sternal dehiscence and wound infections, particularly in high-risk patients.

\section{Class IIb Recommendation; Level of Evidence $=B$.}

Sternal wires to close the sternum may be passed around the sternum (parasternal) or through it (transsternal). Sternal instability arises from the wires cutting through the sternum because of the pressure of the wires in contact with the lateral sternal edges that hold the sternum together. A figure-of-eight wire technique reduces the longitudinal motion at the sternotomy site, whereas a simple cerclage technique, passing the wires around the sternum, does not. Figure-of-eight cable wires are much more flexible than steel wires and conform more tightly to the sternum. In a randomized trial of 700 high-risk patients comparing a simple transsternal wire closure with a figure-of-eight closure, the figure-of-eight closure was associated with a small but significantly decreased incidence of superficial $(0 \%$ vs $2 \%)$ and deep $(0 \%$ vs $1.7 \%)$ wound infections ${ }^{69}$ In an observational study comparing 7835 patients in whom figure-of-eight steel wires were used with 2122 patients in whom single, interrupted wires were used, the incidence of dehiscence was significantly lower in the figure-of-eight group $(0.06 \%$ vs $0.66 \%$; $P<.001){ }^{70}$ However, in a smaller prospective series comparing these 2 techniques in 195 patients there was no difference in the incidence of sternal dehiscence. ${ }^{71}$ DiMarco and colleagues $^{72}$ used an interlocking figure-of-eight sternal closure technique in 978 consecutive patients without a single case of sternal dehiscence or mediastinitis. Figure-ofeight closure techniques seem to increase the strength and stability of sternal closures. Because the incidence of sternal dehiscence is low, larger prospective randomized trials will be needed before it can be recommended as the technique of choice for sternal closure in all patients. Nevertheless, it might be especially helpful for those high-risk patients who are more prone to develop sternal dehiscence. These risk factors include insulin-dependent diabetes, obesity (body mass index $[\mathrm{BMI}]>30 \mathrm{~kg} / \mathrm{m}^{2}$ ), chronic obstructive pulmonary disease, reoperations, and bilateral internal mammary grafting. 


\section{TABLE 2. Summary and recommendations}

The prevention and treatment of sternal wound infections is multifactorial: here we summarize our recommendations to eliminate sternal wound infections.

Obtain nasal swabs or PCR testing if available on all cardiac surgery patients (Class I Recommendation; Level of Evidence $=A$ ).

Administer intranasal mupirocin within $24 \mathrm{~h}$ of surgery and continue for $5 \mathrm{~d}$ in all patients in the absence of negative PCR testing or a negative nasal swab for staphylococcal organisms (Class I Recommendation; Level of Evidence $=B$ ).

Perform a chlorhexidine bath or shower on the evening before surgery (Class IIb Recommendation; Level of Evidence $=B$ ).

Administer a cephalosporin antibiotic intravenously within $60 \mathrm{~min}$ of surgery, continue for procedures of more than $4 \mathrm{~h}$, and for not more than $48 \mathrm{~h}$. The dosing should be weight based (Class I Recommendation; Level of Evidence $=A$ ).

Restrict vancomycin to patients with a history of type 1 allergic reactions to $\beta$-lactam agents or in those patients in whom MRSA is of special concern (Class IIa Recommendation; Level of Evidence $=B$ ).

Do not use vancomycin as the sole prophylactic antibiotic for cardiac surgical procedures (Class III Recommendation; Level of Evidence $=$ B).

Vancomycin should be administered intravenously between 60 and 120 min before the incision and at most for only 1 additional dose when it is used with cephalosporin (Class I Recommendation; Level of Evidence $=A$ ).

An aminoglycoside should be added for 1 preoperative and, at most, 1 additional dose for gram-negative coverage when vancomycin is the primary prophylactic antibiotic (Class IIa Recommendation; Level of Evidence $=C$ ).

Patients with preoperative hypoalbuminemia should have their surgery postponed to receive enteral nutrition for 7-10 d if the procedure can be safely delayed (Class I Recommendation; Level of Evidence $=B$ ).

All distant extrathoracic infections should be treated before cardiac surgical procedures if the procedure can be safely delayed (Class I Recommendation; Level of Evidence $=C$ ).

Smoking cessation and aggressive pulmonary toilet should be performed in patients who are active smokers and in those with chronic obstructive pulmonary disease and in whom surgery can be safely delayed (Class I Recommendation; Level of Evidence $=B$ ).

Continuous insulin infusions should be instituted in patients with glucose levels $>200 \mathrm{mg} / \mathrm{dL}$ preoperatively, and in all patients to keep serum glucose level $<180 \mathrm{mg} / \mathrm{dL}$ during surgery and for at least $24 \mathrm{~h}$ postoperatively (Class I Recommendation; Level of Evidence $=A$ ).

Topical antibiotics (vancomycin) should be applied to the cut edges of the sternum on opening and before closing in all cardiac surgical procedures involving a median sternotomy (Class I Recommendation; Level of Evidence $=B$ ).

Bone wax should not be applied to the cut edges of the sternum at any time (Class III Recommendation; Level of Evidence $=B$ ).

Closing the sternum using a figure-of-eight technique may be preferable to prevent sternal dehiscence and infections (Class IIb Recommendation; Level of Evidence $=B$ ).

Closing a sternum with multiple fractures using the Robicsek weave technique may prevent sternal dehiscence and wound infection (Class IIa Recommendation; Level of Evidence $=B$ ).

The following is a summary for recommendations for management of sternal infections:

Use of dilute povidone-iodine irrigation for the treatment of deep sternal wound infections and mediastinitis should be avoided (Class III Recommendation; Level of Evidence $=B$ ).

Negative pressure wound therapy should be initiated whenever possible in patients when delayed sternal closure is anticipated following deep sternal wound infections (Class IIa Recommendation; Level of Evidence $=B$ ).

A dressing barrier between the sponge and heart and great vessels is necessary when using negative pressure wound therapy to prevent tissue erosion resulting in fatal hemorrhage (Class IIa Recommendation; Level of Evidence =B).

- Closing the sternum with multiple fractures using the Robicsek weave technique may prevent dehiscence and wound infections.

\section{Class IIa Recommendation; Level of Evidence $=B$.}

Although the role of figure-of-eight closures remains unclear for all patients, there is evidence that the use of a Robicsek weave for patients with multiple fractures and those with increased risk factors (diabetes, chronic obstructive pulmonary disease, obesity) decreases the incidence of sternal dehiscence and infections. ${ }^{73,74}$ In the Robicsek technique, the wires are woven through the intercostal spaces parasternally in conjunction with the standard wires that are placed in a transverse fashion across the sternum and the woven parasternal wires. In a retrospective review, in obese $\left(\mathrm{BMI}>30 \mathrm{~kg} / \mathrm{m}^{2}\right)$ and nonobese patients undergoing a sternotomy, the Robicsek technique decreased the incidence of sternal dehiscence to $0 \%$ compared with $6.15 \%$ for simple closure. ${ }^{73}$ In a randomized trial involving 815 patients undergoing high-risk sternotomy, the Robicsek closure reduced the incidence of sternal dehiscence from $3.7 \%$ to $2.5 \%$, although this was not significant. ${ }^{74}$ However, not all of the patients in this series had sternal fractures in addition to the traditional risk factors; this group of patients that may benefit the most from the Robicsek weave technique.

- Rigid sternal fixation with bands or plates may reduce sternal dehiscence and wound infections.

Class IIb Recommendation; Level of Evidence $=B$. 
Rigid sternal fixation techniques include sternal bands or plates. The results have been mixed. Some studies have shown that rigid fixation results in decreased pain and in better sternal stability in high-risk patients, ${ }^{75,76}$ but others have reported that rigid sternal fixation does not alter the risk for wound healing or infections. ${ }^{77,78}$ These techniques are more expensive and have been associated with wound seromas and hematomas. They are contraindicated in patients with osteoporosis or in whom there is an active infection. They are not indicated for uncomplicated sternal closures and should be used only in high-risk patients.

\section{RECOMMENDATIONS FOR POSTOPERATIVE PREVENTION OF STERNAL INFECTIONS External Chest Support Vest}

- External chest support vests may limit the incidence of sternal dehiscence and infections.

$$
\text { Class IIb Recommendation; Level of Evidence }=B \text {. }
$$

External chest support devices consist of pads placed on either side of the sternum to prevent intrinsic movement of the 2 lateral halves and act as shock absorbers. In a prospective multicenter trial where vests were applied 48 hours after surgery and worn for 6 weeks, there was a significant decrease in the incidence of dehiscence, DSWI, and length of hospital stay. ${ }^{79}$ However, these vests are cumbersome and difficult to wear and patient compliance, especially after hospital discharge, may be poor. More clinical trials are necessary to determine the role of these vests.

\section{Antibiotics}

- Appropriate antibiotics should be continued postoperatively for no longer than 48 hours.

\section{Class I Recommendation; Level of Evidence $=A$.}

In a review of major clinical trials, Ariano and Zhanel ${ }^{80}$ reported that antibiotic prophylaxis was recommended for the first 2 postoperative days after coronary bypass surgery. Additional meta-analyses concluded that there was no further advantage to extend prophylactic antibiotics for more than 48 hours. ${ }^{81}$ Hence, the Society of Thoracic Surgeons (STS) guidelines have recommended that prophylactic antibiotics be given for 48 hours or less. ${ }^{43}$

- Continuous insulin infusion should be initiated in the ICU for at least 24 hours to maintain serum glucose level $<180 \mathrm{mg} / \mathrm{dL}$.

$$
\text { Class I Recommendation; Level of Evidence }=A \text {. }
$$

Numerous studies have shown that maintaining serum glucose level $<180 \mathrm{mg} / \mathrm{dL}$ for at least the first 24 hours in the ICU, and if necessary for the entire ICU period, has resulted in a significant decrease in the incidence of sternal wound infections. ${ }^{37,38,50}$ This is currently a Class I recommendation from the STS practice guidelines on blood glucose management during adult cardiac surgery. ${ }^{82}$

\section{RETAINED BLOOD, EARLY EXTUBATION, INDWELLING CATHETERS}

There are several other important postoperative factors that can contribute to an increased incidence of sternal wound infections and should be avoided. Retained blood coagulum is an excellent culture medium, therefore every attempt should be made to achieve hemostasis to avoid a return to the operating room for bleeding complications, which have been associated with an increased risk of wound infections. $^{83}$ Early extubation may also decrease the incidence of wound complications. ${ }^{84}$ Early removal of indwelling urinary and central venous catheters have also been found to significantly decrease the incidence of wound infections. ${ }^{85}$

\section{RECOMMENDATIONS FOR MANAGEMENT OF STERNAL INFECTIONS}

Despite close adherence to these guidelines, wound infections may still occur. The treatment of sternal wound infections must be individualized based on the depth of the infection, the organisms that are cultured, and the patient's clinical status. In this section, we review those principles that will help to achieve the lowest morbidity and mortality in treatment of sternal wound infections.

Treatment of superficial infections includes incision and drainage to allow unimpeded drainage of the purulent material and packing the wound with dressing changes. In addition to packing, negative pressure wound therapy (NPWT) can also be used.

Treatment of deep infections may be individualized as noted above, but the principles of treatment are standard. They include debridement of all devitalized and necrotic tissue, drainage of all infected spaces, antibiotic therapy, and techniques to achieve closure of the sternal space.

After sternal debridement, the wound can be closed immediately or delayed. Immediate closure can be performed if the deep mediastinal tissues are free of infection, there is enough sternum to reapproximate and achieve stability, and the patient is clinically stable. In those instances where sternal closure is possible, but there is still mediastinal infection, continuous irrigation of the wound with drainage tubes has been performed.

- Use of dilute povidone-iodine irrigation for the treatment of DSWI in mediastinitis should be avoided.

Class III Recommendation; Level of Evidence $=B$. 
Continuous mediastinal irrigation with a povidoneiodine solution was previously the standard solution used for mediastinal irrigation. However, animal experiments have found that absorption of iodine following continuous wound irrigation is exceedingly high. ${ }^{86}$ Systemic absorption of iodine during mediastinal irrigation has been associated with complications including renal failure and electrolyte disturbances, changes in iodine metabolism, abnormal thyroid function, changes in mental status, and seizures. ${ }^{87-89}$ Its use has been replaced by dilute antibiotic irrigation solutions.

In those patients who are not candidates for primary wound closure, sternal wound flap closure with the pectoralis major, latissimus dorsi, or rectus abdominis muscles along with omental flaps are the procedure of choice. ${ }^{90-92}$ However, many patients may not be candidates for immediate wound closure with a flap procedure because of persistent mediastinitis and undrained mediastinal spaces. NPWT has emerged as a bridge to surgical closure in patients with persistent deep sternal infections.

- NPWT should be initiated whenever possible in patients in whom delayed sternal closure is anticipated following DSWI.

\section{Class IIa Recommendation; Level of Evidence $=B$.}

NPWT is a wound dressing system that continuously or intermittently applies subatmospheric pressure to the surface of the wound. It stabilizes the chest wall and allows for earlier extubation, ${ }^{93}$ removes excess tissue fluid, and decreases wound edema. ${ }^{94}$ Wound healing and granulation tissue are accelerated. It has been shown to increase sternal blood flow in an experimental porcine model. ${ }^{95}$ NPWT therapy has also been associated with improved early and long-term survival in patients with DSWI. ${ }^{96,97}$

Although there are no randomized trials comparing NPWT with the standard therapy of debridement with dressing changes followed by flap closure, there are a number of retrospective reviews. Fuchs and colleagues ${ }^{98}$ compared NPWT with drainage, open dressings, and flap closure, and found that patients treated with NPWT had reduced hospital stay and a shorter time to achieve negative wound cultures, and a reduced percentage of patients were discharged with an open sternum. Raja and Berg ${ }^{99}$ found that NPWT reduced the time interval between sternal debridement and complete closure (either primary or flap coverage) of the wound. Petzina and colleagues, ${ }^{100}$ in a retrospective analysis of 118 patients with poststernotomy mediastinitis, found that the mortality with NPWT was $6 \%$ compared with $25 \%$ in patients treated with debridement and dressing changes without NPWT.

- When using NPWT, it is necessary to place a barrier dressing between the sponge and the heart and great vessels to prevent tissue erosion resulting in fatal hemorrhage.

\section{Class II Recommendation; Level of Evidence $=B$.}

Fatal exsanguination has been reported with NPWT from injuries to the exposed myocardium, great vessels, and bypass conduits. ${ }^{101,102}$ Therefore, it is important to place a barrier dressing between the gauze or foam and the heart to minimize the delivery of excessive negative pressure to the exposed myocardium, great vessels, or bypass conduits.

\section{References}

1. Braxton JH, Marrin CA, McGrath PD, Ross CS, Morton JR, Norotsky M, et al. Mediastinitis and long-term survival after coronary artery bypass graft surgery. Ann Thorac Surg. 2000;70:2004-7.

2. Milano CA, Kesler K, Archibald N, Sexton DJ, Jones RH. Mediastinitis after coronary artery bypass graft surgery. Risk factors and long-term survival. Circulation. 1995;92:2245-51.

3. El Oakley RM, Wright JE. Postoperative mediastinitis: classification and management. Ann Thorac Surg. 1996;61:1030-6.

4. Ferris TG, Torchiana DF. Public release of clinical outcomes data - online CABG report cards. N Engl J Med. 2010;363:1593-5.

5. Centers for Medicare \& Medicaid Services. Hospital-acquired conditions (present on admission indicator). Available at: http://www.cms.hhs.gov/hospitalacqcond/. Accessed 2014.

6. Liberati A, Altman DG, Tetzlaff J, Moher D. The PRISMA statement for reporting systemic reviews and meta-analyses of studies that evaluate health care interventions: explanation and elaboration. J Clin Epidemiol. 2009;62:e1-34.

7. Ridderstolpe L, Gill H, Granfeldt H, Ahlfeldt H, Rutberg H. Superficial and deep sternal wound complications: incidence, risk factors, and mortality. Eur J Cardiothorac Surg. 2001;20:1168-75.

8. Garner JS, Jarvis WR, Emori TG, Horan TC, Hughes JM. CDC definitions for nosocomial infections. Am J Infect Control. 1988;16:128-40.

9. Huang SS, Rifas-Shiman SL, Warren DK, et al. Improving methicillin-resistant Staphylococcus aureus surveillance and reporting in intensive care units. $J$ Infect Dis. 2007; 195:330-8.

10. Wertheim HF, Vos MC, Oh A, et al. Risk and outcome of nosocomial Staphylococcus aureus bacteremia in nasal carriers versus non-carriers. Lancet. 2004;364:703-5.

11. Pujol M, Pena C, Pallarea R, et al. Nosocomial Staphylococcus aureus bacteremia among nasal carriers of methicillin-resistant and methicillinsusceptible strains. Am J Med. 1996;100:509-16.

12. Doebbeling BN, Breneman DL, Neu HC, et al. Elimination of Staphylococcus aureus nasal carriage in health care workers: analysis of six clinical trials with calcium mupirocin ointment. The Mupirocin Collaborative Study Group. Clin Infect Dis. 1993;17:466-74.

13. Harbarth S, Dharan S, Liassine N, Herman HP, Auckenthaler R, Pittet D. Randomized, placebo-controlled, double-blind trial to evaluate the efficacy of mupirocin for eradicatory carriage of methicillin-resistant. Staphylococcus aureus. Antimicrob Agents Chemother. 1999;43:1412-6.

14. Dryden MS, Dailly S, Crouch M. A randomized, controlled trial of three topical preparations versus a standard topical regimen for the clearance of MRSA colonization. J Hosp Infect. 2004;56:283-6.

15. San Juan R, Chaves F, Lopez Gude MJ, Diaz-Pedroche C, Otero J, Cortina Romero JM, et al. Staphylococcus aureus post-sternotomy mediastinitis: description of two distinct acquisition pathways with different potential preventive approaches. J Thorac Cardiovasc Surg. 2007;134:670-6.

16. Cimochowski G, Harestock M, Brown R, Bernardi M, Alonzo N, Coyle K. Intranasal mupirocin reduces sternal wound infection after open heart surgery in diabetics and non-diabetics. Ann Thorac Surg. 2001;71:1572-9.

17. Bode LGM, Kloytmans JA, Werthiem HF, Bogaers D, VandenbrouckeGrauls CM, Roosendaal R, et al. Preventing surgical-site infections in nasal carriers of Staphylococcus aureus. N Engl J Med. 2010;362:9-17.

18. Laupland KB, Conly JM. Treatment of Staphylococcus aureus colonization and prophylaxis for infected topical intranasal mupirocin: an evidence-based review. Clin Infect Dis. 2003;37:933-8. 
19. Perl TM, Cullen JJ, Wenzel RP. Intranasal mupirocin to prevent postoperative Staphylococcus aureus infections. N Engl J Med. 2002;346:1871-7.

20. Shrestha NK, Banbury MK, Weser M. Safety of targeted perioperative mupirocin treatment for preventing infections after cardiac surgery. Ann Thorac Surg. 2006;81:2183-8.

21. Konualinka A, Errett L, Fong IW. Impact of treating Staphylococcus aureus nasal carriers on wound infections in cardiac surgery. J Hosp Infect. 2006;64:162-8.

22. Kalmeiser MD, Coertjens H, van Nieuwland-Bollen PM, et al. Surgical site infections in orthopedic surgery: the effect of mupirocin nasal ointment in a double-blind, randomized, placebo-controlled study. Clin Infect Dis. 2002;35: 353-8.

23. Kamel C, McGahan L, Polisena J, Mierzwinski-Urban J, Embil JM. Preoperative skin antiseptic preparations for preventing surgical site infections: a systemic review. Infect Control Hosp Epidemiol. 2012;33:608-17.

24. Kuhme T, Isuksson B, Dahlin LG. Wound contamination in cardiac surgery. A systematic quantitative and qualitative study of the bacterial growth in sternal wounds in cardiac surgery patients. APMIS. 2007;115:1001-7.

25. Rady MY, Ryan T, Starr NJ. Clinical characteristics of preoperative hypoalbuminemia predict outcome of cardiovascular surgery. J Parenter Enteral Nutr. 1997;21:81.

26. Engelman DT, Adams DH, Byrne JG, Ranki SF, Collins JJ, Caper GS, et al. Impact of body mass index and albumin on morbidity and mortality after cardiac surgery. J Thorac Cardiovasc Surg. 1999;118:866-73.

27. Ulicny KS Jr, Hiratzka LF. The risk factors of median sternotomy infection: a current review. J Card Surg. 1991;6:338-51.

28. Gibbs L, Kakis A, Weinstein P, Conte J. Bone wax as a risk factor for surgical site infection following neurospinal surgery. Infect Control Hosp Epidemiol. 2004:25:346-8

29. Rich MW, Keller SJ, Schechtman KB, Marshall WG Jr, Kouchoukos NJ. Increased complications and prolonged hospital stay in elderly cardiac surgical patients with low serum albumin. Am J Cardiol. 1989;63:714-8.

30. Gibbs J, Cull W, Henderson W, Daley J, Hurk T, Khuri SF. Preoperative serum albumen level as a predictor of operative mortality and morbidity: results from the National VA Surgical Risk Study. Arch Surg. 1999; $134: 36-42$

31. Reinhardt GF, Myscofski JW, Wildens DB, et al. Incidence and mortality of hypoalbuminemic patients hospitalized veterans. J Parenter Enteral Nutr. 1980;4:357-9.

32. Aspen Board of Directors and The Clinical Guidelines Task Force. Guidelines for the use of parental and enteral nutrition in adult and pediatric patients. J Parenter Enteral Nutr. 2002;26:15A-138A.

33. Jie B, Jiang ZM, Nolan MT, et al. Impact of preoperative nutritional support on clinical outcome in abdominal surgical patients at nutritional risk. Nutrition. 2012;28:1022-6.

34. Edwards LD. The epidemiology of 2056 remote site infections and 1,996 surgical wound infections occurring in 1865 patients: a four year study of 40,923 operations at Rush-Presbyterian-St. Luke's Hospital, Chicago. Ann Surg. 1976;184:758-66.

35. Mangram AJ, Horan TC, Pearson ML, Silver LC, Jarvis WR. Guideline for prevention of surgical site infections. Infect Control Hosp Epidemiol. 1999; 20:250-78.

36. Anderson DJ, Kaye KS, Classen D, et al. Strategies to prevent surgical site infections in acute care hospitals. Infect Control Hosp Epidemiol. 2008;29: S51-61.

37. Zerr K, Furnary A, Grunkemeier G, et al. Glucose control lowers the risk of wound infection in diabetic patients after open heart operations. Ann Thorac Surg. 1997;63:356-61

38. Lazar HL, Chipkin SR, Fitzgerald CA, et al. Tight glycemic control in diabetic coronary artery bypass graft patients improves perioperative outcomes and decreases recurrent ischemic events. Circulation. 2004;109:1497-502.

39. Sepehripour AH, Lot T, McCormick DJ, Shipolini AR. Is there benefit in smoking cessation prior to cardiac surgery? Interact Cardiovasc Thorac Surg. 2012; $15: 726-32$.

40. Jones R, Nyawo B, Jamieson S, Clark S. Current smoking predicts increased operative mortality and morbidity after cardiac surgery in the elderly. Interact Cardiovasc Thorac Surg. 2011;12:449.

41. Nagachinta T, Stephens M, Reitz B, Polk BF. Risk factors for surgical wound infections following cardiac surgery. J Infect Dis. 1987;156:967.

42. Engelman R, Shahian D, Shemin R, Guy TS, Bratzler D, Edwards F, et al. The Society of Thoracic Surgeons practice guideline series: antibiotic prophylaxis in cardiac surgery, part II: antibiotic choice. Ann Thorac Surg. 2007;83: 1569-76.

43. Edwards FH, Engelman RM, Houck P, Shahian DM, Bridges CR. The Society of Thoracic Surgeons practice guidelines series: antibiotic prophylaxis in cardiac surgery, part I: duration. Ann Thorac Surg. 2006;81:397-404.

44. Lewis DR, Longman RJ, Wisheart JD, Spencer RC, Brown NM. The pharmacokinetics of a single dose of gentamicin $(4 \mathrm{mg} / \mathrm{kg})$ as prophylaxis in cardiac surgery requiring cardiopulmonary bypass. Cardiovasc Surg. 1999;7: 398-401.

45. Zanetti G, Giardina R, Platt R. Intraoperative redosing of cefazolin and risk for surgical site infection in cardiac surgery. Emerg Infect Dis. 2001;7:828-31.

46. Caffarelli AD, Holden JP, Baron EJ, Lemmens HJ, D’Souze H, Yau V, et al Plasma cefazolin levels during cardiovascular surgery: effects of cardiopulmonary bypass and profound hypothermic circulatory arrest. J Thorac Cardiovasc Surg. 2006;131:1338-43.

47. Doenst T, Wijeysundera D, Karkouti K, et al. Hyperglycemia during cardiopulmonary bypass is an independent risk factor for mortality in patients undergoing cardiac surgery. J Thorac Cardiovasc Surg. 2005;130:1144-9.

48. Fish LH, Weaver TW, Moore AL, Steel LG. Value of postoperative blood glucose in predicting complications and length of stay after coronary artery bypass grafting. Am J Cardiol. 2003;92:74-6.

49. Gandhi GY, Nuttall GA, Abel MD, et al. Intraoperative hyperglycemia and perioperative outcomes in cardiac surgery patients. Mayo Clin Proc. 2005;80: $862-6$.

50. Furnary AP, Gao G, Grunkemeier GL, et al. Continuous insulin infusion reduces mortality in patients with diabetes undergoing coronary artery bypass grafting. J Thorac Cardiovasc Surg. 2003;125:1007-21.

51. Vander Salm TJ, Okike ON, Pasque MK, Pezzella AT, Lew R, Traina V, et al. Reduction of sternal infection by application of topical vancomycin. $J$ Thorac Cardiovasc Surg. 1989;98:618-22.

52. Lazar HL, Ketchedjian A, Haime M, Karlson K, Cabral H. Topical vancomycin in combination with perioperative antibiotics and tight glycemic control helps to eliminate sternal wound infections. J Thorac Cardiovasc Surg. 2014;148: 1035-40.

53. Arruda MVF, Braile DM, Joaquim MR, Suzuki FA, Alves RH. The use of vancomycin paste for sternal hemostasis and mediastinitis prophylaxis. Rev Bras Circ Cardiovasc. 2008;23:35-9.

54. Lazar HL, Barlam T, Cabral H. The effect of topical vancomycin applied to sternotomy incisions on postoperative serum vancomycin levels. J Card Surg. 2011;26:461-5

55. Friberg O, Svedjeholm R, Wudequist B, Granfeldlt H, Viker-fors T, Kallman J. Local gentamicin reduces sternal wound infections after cardiac surgery: a randomized controlled trial. Ann Thorac Surg. 2005;79:153-62.

56. Eklund AM, Valtonen M, Werkkala KA. Prophylaxis of sternal wound infections with gentamicin - collagen implant: randomized controlled study in cardiac surgery. J Hosp Infect. 2005;59:108-12.

57. Friberg O, Svedjeholm R, Kallman J, Soderquist B. Incidence, microbiological findings, and clinical presentation of wound infections after cardiac surgery with and without local gentamicin prophylaxis. Eur J Clin Microbiol Infect Dis. 2007;26:91-7.

58. Friberg O. Local collagen-gentamicin for prevention of sternal wound infections. The LOGIP trial. APMIS. 2007;115:1016-21.

59. Bennett-Guerrero E, Ferguson TB Jr, Lin M, Garg J, Mark DB, Scavo VA Jr, et al. Effect of an implantable gentamicin-collagen sponge on sternal wound infections following cardiac surgery - a randomized trial. JAMA. 2010;304: 755-62.

60. Kowalewski M, Pawliszak W, Zaborowska ME, et al. Gentamicin-collagen sponge reduces the risk of sternal wound infections following heart surgery. Meta-analysis. J Thorac Cardiovasc Surg. 2015;149:1631-40.

61. Wang MY, Armstrong JK, Fischer TC, Meiselman HJ, McComb GJ, Levy ML. A new, pluronic-based bone hemostatic agent that does not impair osteogenesis. Neurosurgery. 2001;49:962-8.

62. Noah N, Abdullah WA, Grawish ME, Ramalingam S, Javed F, Al-Hezaimi K. The effects of surgical and bone wax hemostatic agents on bone healing - an experimental study. Indian J Orthop. 2014;48:319-25.

63. Vestergaard RF, Jensen H, Vind-Kezvnovic S, Jakobsen T, Sobulle K, Hasenkam JM. Bone healing after median sternotomy. A comparison of two hemostatic devices. J Cardiothorac Surg. 2010;5:117-24.

64. Steingrimsson S, Gustafsson R, Gudbjartsson T, Mokhtari A Ingemansson R, Sjogren J. Sternocutaneous fistulas after cardiac surgery: 
incidence and late outcome during a ten-year follow-up. Ann Thorac Surg. 2009;88:1910-5.

65. Prziborowski J, Hartrumpf M, Stock VA, Kuehnel RV, Albes JM. Is bone wax safe and does it help? Ann Thorac Surg. 2008;85:1002-6.

66. Ozdemir AC, Aykut K. Efficacy and safety of bone wax to reduce sternal bleeding following coronary bypass surgery. Ann Thorac Cardiovasc Surg. 2013;81:1-4.

67. Bhatti F, Dunning J. Does liberal use of bone wax increase the risk of mediastinitis. Interact Cardiovasc Thorac Surg. 2003;2:410-2.

68. Zeitani J, Penta de Peppo A, Moscarelli M, Guerrieri WL, Scafuri A, Nardi P, et al. Influence of sternal size and inadvertent paramedian sternotomy on stability of the closure site: a clinical and mechanical study. J Thorac Cardiovasc Surg. 2006;132:38-42.

69. Bottio T, Rizzoli G, Viola V, et al. Double crisscross sternal wiring and chest wound infections: a prospective randomized study. J Thorac Cardiovasc Surg. 2003;126:1352.

70. Almdahl SM, Halvorsen P, Veel T, Rynning SE. Avoidance of non-infectious sternal dehiscence: figure of 8 wiring is superior to straight wire closure. Scand Cardiovasc J. 2013;47:247-50.

71. Ramzisham AR, Raflis AR, Khairulasri MG, Ooi SMJ, Fikri AM, Zamrn MD. Figure of 8 vs interrupted sternal wire closure of median sternotomy. Asian Cardiovasc Thorac Ann. 2009; 17:587-91.

72. DiMarco RF, Lee MW, Bekoe S, Grant KJ, Woelfel GF, Pellegrini RV. Interlocking figure of 8 closure of the sternum. Ann Thorac Surg. 1989;47: 927-9.

73. Robicsek F, Daugherty HK, Cook JW. The prevention and treatment of sternum separation following open heart surgery. J Thorac Cardiovasc Surg. 1977;73: 267-75.

74. Schimmer C, Reents W, Berneder S, et al. Prevention of sternal dehiscence and infection in high-risk patients: a perspective randomized multi-center trial. Ann Thorac Surg. 2008;86:1897.

75. Fawzy H, Alhodaib N, Mazer CD, et al. Sternal plating for primary and secondary sternal closure, can it improve sternal stability? J Cardiothorac Surg. 2009;4:19-24.

76. Song DH, Lohman RF, Renucci JD, Jeevanandam V, Raman J. Primary sternal plating in high-risk patients prevents mediastinitis. Eur J Cardiothorac Surg. 2004;26:367-72.

77. Franco S, Herrera AM, Atchortva M, et al. Use of steel bands in sternotomy closure: implications in high-risk cardiac surgical population. Interact Cardiovasc Thorac Surg. 2009;8:200-3.

78. Badellino M, Cavarocchi NC, Kolff J, et al. Sternotomy closure with Parham bands. J Cardiac Surg. 1988;3:235-9.

79. Gorlitzer M, Folkmann S, Meinhart J, et al. A newly-designed thorax support vest prevents sternal instability after median sternotomy. Eur J Cardiothorac Surg. 2009;36:335-9.

80. Ariano R, Zhanel GG. Antimicrobial prophylaxis in coronary bypass surgery: a critical appraisal. DICP. 1991;25:478-84.

81. Kreter B, Woods M. Antibiotic prophylaxis for cardiothoracic operations. Meta-analysis of thirty years of clinical trials. J Thorac Cardiovasc Surg. 1992;104:590-9.

82. Lazar HL, McDonnell M, Chipkan S, Furnary AP, Engelman RM, Sadhu AR, et al. The Society of Thoracic Surgeons practice guideline series: blood glucose management during adult cardiac surgery. Ann Thorac Surg. 2009; 87:663-9.

83. Boeken V, Eisner J, Feindt P, Petzold TH, Schulte HD, Game E. Does the time of resternotomy for bleeding have any influence on the incidence of sternal infections, septic courses or further complications? J Thorac Cardiovasc Surg. 2001;49:45-8.

84. Graf K, Sohr D, Haverich A, Kuhn C, Gastmeier P, Chaberny IF. Decrease of deep sternal surgical site infections rates after cardiac surgery by a comprehensive infection control program. Interact Cardiovasc Thorac Surg. 2009;9:282-6.
85. LeGuillou V, Tavolacci MP, Baste JM, Hubscher C, Bedost E, Bessou JP, et al. Surgical site infection after central venous catheter-related infection in cardiac surgery. Analysis of a cohort of 7557 patients. J Hosp Infect. 2011;79:236-41.

86. Glick PL, Guglielmo BJ, Tranbaugh RF, Turkey K. Iodine toxicity in a patient treated by continuous povidone-iodine mediastinal irrigation. Ann Thorac Surg. 1985;39:478-80.

87. Glick PL, Guglielmo BJ, Winter ME, Finkbeiner W, Kirley K. Iodine toxicity secondary to continuous povidone-iodine mediastinal irrigation in dogs. J Surg Res. 1990;49:428-34.

88. Zec N, Donovan JW, Aufiero TX, Kincaid RF, Demers LM. Seizures in a patient treated with continuous povidone-iodine mediastinal irrigation. $N$ Engl J Med. 1992;326:1784.

89. Campistol JM, Abad C, Nogue S, Bertran A. Acute renal failure in a patient treated by continuous povidone-iodine mediastinal irrigation. J Cardiovasc Surg (Torino). 1988;29:410-2.

90. Jones G, Jurkiewicz MJ, Bostwick J, et al. Management of the infected median sternotomy wound with muscle flaps. The Emory 20-year experience. Ann Surg. 1997;225:766-76.

91. Rand RP, Cochran RP, Aziz S, et al. Prospective trial of catheter irrigation and muscle flaps for sternal wound infection. Ann Thorac Surg. 1998;65: 1046-9.

92. Hugo NE, Sultan MR, Ascherman JA, Patsis MC, Smith CR, Rose EA. Single-stage management of 74 consecutive sternal wound complications with pectoralis major myocutaneous advancement flaps. Plast Reconstr Surg. 1994;93:1433-41.

93. Sjoegren J, Gustafsson R, Milsson J, Malmsjoe M, Ingemansson R. Clinical outcome after poststernotomy mediastinitis: vacuum-assisted closure versus conventional treatment. Ann Thorac Surg. 2005;79:2049-55.

94. Argenta LC, Marykwas MJ. Vacuum-assisted closure. A new method for wound control and treatment: clinical experience. Ann Plast Surg. 1997;38: 563-77.

95. Wackenfors A, Gustafsson R, Sjogren J, Algotssor L, Zngemanssor R, Malmsjo M. Blood flow responses in the peristernal thoracic wall during vacuum-assisted closure therapy. Ann Thorac Surg. 2005;79:1724-30.

96. Cayci C, Russo M, Cheema FH, et al. Risk analysis of deep sternal wound infections and their impact on long-term survival: a propensity analysis. Ann Plast Surg. 2008;61:294-301.

97. Baillot R, Cloutier D, Montalin L, et al. Impact of deep sternal wound infection management with vacuum-assisted closure therapy followed by sternal osteosynthesis: a 15-year review of 23,499 sternotomies. Eur J Cardiothorac Surg. 2010;37:880-7.

98. Fuchs V, Zittermann A, Stuettgen B, et al. Clinical outcome of patients with deep sternal wound infection managed by vacuum-assisted closure compared to conventional therapy with open packing: a retrospective analysis. Ann Thorac Surg. 2005;79:516-21.

99. Raja SG, Berg GA. Should vacuum-assisted closure therapy be routinely used for management of deep sternal wound infection after cardiac surgery? Interact Cardiovasc Thorac Surg. 2007;6:523-6.

100. Petzina R, Hoffman J, Navasardyan A, et al. Negative pressure wand therapy for post-sternotomy mediastinitis reduces mortality rate and sternal re-infection rate compared to conventional treatment. Eur J Cardiothorac Surg. 2010;38: 110-6.

101. Mokhtari A, Petzina R, Gustafsson L, Sjogren S, Malmsjo M, Ingemansson R. Sternal stability at different negative pressures during vacuum-assisted closure therapy. Ann Thorac Surg. 2006;82:1063-7.

102. Abu-Omas Y, Naik MS, Catarino PA, Ratnatunga C. Right ventricular rupture during use of high-pressure suction drainage in the management of poststernotomy mediastinitis. Ann Thorac Surg. 2003;76:974-6.

Key Words: guidelines, prevention, sternal wound infection, treatment 